\title{
Motion - Prophylactic banding of esophageal varices is useful: Arguments against the motion
}

\author{
Kris V Kowdley MD FACP
}

KV Kowdley. Motion - Prophylactic banding of esophageal varices is useful: Arguments against the motion. Can J Gastroenterol 2002;16(10):693-695.

Bleeding from esophageal varices leads to substantial morbidity and mortality. Despite advances in pharmacological and endoscopic therapy, as well as general supportive care, the mortality rate associated with acute variceal hemorrhage has not improved significantly over the past two decades. Prophylactic therapy with nonselective beta-blockers or long acting nitrates reduces the incidence of variceal bleeding in patients with cirrhosis, is cost effective and may improve survival. Surgical portosystemic shunting reduces the risk of bleeding but is associated with significant operative mortality and a high risk of portosystemic encephalopathy. Endoscopic sclerotherapy causes adverse effects in a large proportion of patients and is, therefore, not suitable for primary prophylaxis of bleeding. Although variceal band ligation is effective in reducing the rate of bleeding and is safer than sclerotherapy, it has not been shown to provide a survival advantage compared with beta-blockers. A significant reduction in the rate of variceal bleeding with band ligation, compared with betablockers, was shown in only one study. Beta-blockers offer several advantages, including low cost, ease of use and safety. The available data do not yet support the prophylactic use of variceal band ligation, and this procedure should be reserved for patients who are either unwilling or unable to take beta-blockers. It is hoped that additional large, multicentre trials of band ligation versus beta-blockers will examine the efficacy, cost effectiveness and impact on quality of life among patients with cirrhosis.

Key Words: Band ligation; Beta-blockers; Cirrhosis; Endoscopic sclerotherapy; Esophageal varices

\section{Proposition - La ligature prophylactique des varices œsophagiennes est utile : arguments défavorables}

RÉSUMÉ : Les hémorragies par varices œsophagiennes entraînent une forte morbidité et une forte mortalité. Malgré les progrès réalisés dans le domaine des traitements médicamenteux et endoscopique, ainsi que dans les soins généraux de soutien, le taux de mortalité associé aux hémorragies variqueuses aiguës n'a pas diminué de façon significative au cours des vingt dernières années. Le traitement prophylactique aux bêta-bloquants non sélectifs ou aux nitrates à action prolongée diminue l'incidence des hémorragies variqueuses chez les patients atteints de cirrhose, est économique et peut accroître le taux de survie. La dérivation porto-systémique diminue certes les risques d'hémorragie, mais elle est associée à un fort taux de mortalité opératoire et à un risque élevé d'encéphalopathie hépatique. La sclérothérapie endoscopique provoque des effets indésirables chez un grand nombre de patients; elle ne convient donc pas à la prophylaxie des hémorragies. Même si la ligature élastique des varices permet de diminuer le taux d'hémorragie et qu'elle se révèle plus sûre que la sclérothérapie, elle ne semble pas plus efficace que les bêta-bloquants sur le plan de la survie. Une seule étude a montré que la ligature élastique avait eu pour résultat une diminution significative du taux d'hémorragie par rapport aux bêta-bloquants. De plus, ces derniers offrent plusieurs avantages : faible coût, facilité d'utilisation, innocuité. Les données existantes jusqu'à maintenant ne permettent pas de justifier le recours à la ligature élastique à des fins prophylactiques; le traitement ne devrait être réservé qu'aux patients qui ne veulent pas ou ne peuvent pas prendre de bêta-bloquants. Il est à espérer que d'autres essais multicentres, de grande taille, seront menés afin de comparer la ligature élastique et les bêta-bloquants sur les plans de l'efficacité, du rapport coût-efficacité et de l'incidence sur la qualité de vie des patients cirrhotiques.

This article was originally presented at a symposium entitled, "Controversies in Gastroenterology", sponsored by Axcan Pharma, Toronto, Ontario, April 8 to 10,2002

Division of Gastroenterology and Hepatology, University of Washington School of Medicine, Seattle, Washington, USA

Correspondence: Dr Kris V Kowdley, Division of Gastroenterology and Hepatology, University of Washington School of Medicine, Seattle,

Washington 98195, USA. Telephone 206-598-2076, fax 206-598-3884, e-mail kkowdley@u.washington.edu 
sophageal varices are a major cause of admission to hos-

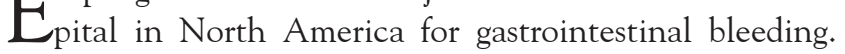
The direct costs associated with variceal bleeding among patients with cirrhosis were estimated at more than US $\$ 4$ billion as far back as 20 years ago. Furthermore, despite advances in supportive care and specific pharmacological and endoscopic therapy, the mortality from an episode of variceal hemorrhage has not changed significantly since that time. One explanation for this disappointing fact is that many patients experience catastrophic hemorrhage and are thus unable to reach an intensive care setting for treatment. Of patients who are admitted to hospital for their first episode of variceal hemorrhage, $30 \%$ to $50 \%$ die within six weeks (1).

\section{VARICEAL HEMORRHAGE}

It is reasonable to assume that the early identification of patients with esophageal varices and treatment to prevent the first episode of bleeding may improve the prognosis. Several studies have found that the prevalence of varices in patients with cirrhosis is approximately $60 \%$ (1). Of these patients, $25 \%$ to $40 \%$ experience their first variceal hemorrhage within the first two years of the diagnosis, and most occur within the first year. The major predictors of variceal bleeding include the severity of the underlying liver disease and the size and visual characteristics of the varices. For example, large size and the presence of red wale markings, identified at endoscopy, portend a high risk of variceal bleeding.

The underlying physiological cause of esophageal variceal bleeding is portal hypertension. This state is characterized by increased blood flow in the splanchnic circulation and increased intrahepatic vascular resistance. The degree of portal hypertension is reflected by the hepatic venous pressure gradient (HVPG), which is the difference in pressure between the portal and hepatic veins. It therefore provides a measurement of the portosystemic pressure gradient. A gradient of greater than $12 \mathrm{mmHg}$ is associated with an increased risk of bleeding from esophageal varices, whereas reduction of the HVPG to below this threshold essentially eliminates the risk of variceal bleeding.

\section{PROPHYLACTIC THERAPY}

Primary prophylaxis involves the application of treatment that is designed to prevent the first episode of variceal bleeding in patients with cirrhosis. Several treatment modalities have been tried, including portosystemic shunts, medications (especially beta-adrenergic antagonist and long acting nitrates), endoscopic sclerotherapy, and rubber band ligation. Early studies showed that surgical shunts reduced the risk of bleeding but were associated with unacceptable operative mortality and a high risk of portosystemic encephalopathy. A number of trials, involving more than 1500 patients, have investigated the role of endoscopic sclerotherapy in primary prophylaxis. With some exceptions, the trials found that sclerotherapy was not a worthwhile treatment, even though the risk of bleeding was reduced, largely because of high rates of adverse effects, such as pulmonary complications, fever, chest pain and esophageal ulceration.

The administration of propranolol, a nonselective betablocker, results in a $9 \%$ to $23 \%$ decrease in HVPG. Although this results mainly from a decrease in portal venous inflow due to mesenteric arteriolar vasoconstriction, high doses of this agent may further reduce the HVPG by decreasing the heart rate and cardiac output.

Approximately 1000 patients have been enrolled in nine randomized placebo-controlled trials of beta-blockers, usually propranolol or nadolol, for primary prophylaxis of variceal bleeding (2-4). Unfortunately, the patient populations were not similar in the studies. A 25\% reduction in the resting heart rate was used as a measure of beta-blockade. Treatment with beta-blockers was shown to reduce the relative risk of variceal bleeding by $45 \%$ and to reduce mortality by $20 \%$ after two years of therapy. The risk of death from hemorrhage was reduced by approximately $50 \%$. The rates of first variceal hemorrhage with beta-blockers ranged from a low of $3 \%$ to $5 \%$ to a high of $20 \%$ to $35 \%$, whereas the rates in control subjects were $18 \%$ to $35 \%$. The overall one-year survival rates were $75 \%$ to $95 \%$ in the beta-blocker groups compared with $66 \%$ to $89 \%$ in the control groups. Multivariate analysis revealed that failure to respond to these drugs was associated with young age, large varices, advanced liver disease and low medication dosage. Betablockers are tolerated well by most patients, and fewer than $5 \%$ were withdrawn from the clinical trials because of adverse effects.

Long acting nitrates have also been shown to be effective at reducing the risk of bleeding, but are generally considered to be second-line drugs for patients who do not tolerate beta-blockers. One study found that the combination of beta-blockers and nitrates was associated with a lower rate of bleeding than treatement with beta-blockers alone, but other investigators have not confirmed this.

\section{RUBBER BAND LIGATION}

Band ligation has mainly replaced endoscopic sclerotherapy for the acute treatment of bleeding esophageal varices. The former is more effective than sclerotherapy for acute bleeding, causes fewer complications and requires fewer sessions to eradicate the lesions. It has, therefore, been proposed that band ligation be used in the primary prophylaxis of esophageal varices. Published studies have compared this technique with treatment with either placebo or betablockers. Given the proven safety and efficacy of betablockers in primary prophylaxis, it is generally considered unethical to conduct a placebo-controlled trial.

A prospective, randomized trial involving 126 patients with cirrhosis and endoscopically evaluated high-risk varices found that band ligation decreased the risk of first bleeding compared with untreated controls (19\% versus $60 \%, \mathrm{P}=0.0001$ ) (5). The two-year cumulative mortality rate was lower in the ligation group than in the control group (28\% versus 58\%, $\mathrm{P}=0.0011$ ). Most deaths in the lig- 
ation group were due to liver failure, and not to variceal bleeding. Patients with Child-Pugh class A cirrhosis were most likely to benefit from band ligation.

Another study of 127 patients with cirrhosis with highrisk varices compared band ligation with no active treatment (6). During a mean follow-up period of 29 months, band ligation was associated with a trend toward lower bleeding (22\% versus $35 \%, \mathrm{P}=0.15)$ and mortality $(12.5 \%$ versus $22 \%, \mathrm{P}=0.22)$ rates, but the differences were not statistically significant. The transfusion requirement was significantly lower in the band ligation group than in the control group ( 0.6 versus 1.2 units, $\mathrm{P}<0.001$ ). Slightly more patients died of variceal hemorrhage in the control group than in the ligation group. It appeared that band ligation was especially effective in reducing bleeding in patients with Child-Pugh class B cirrhosis.

Yet another study compared band ligation with propranolol in 89 patients with large varices (more than $5 \mathrm{~mm}$ in diameter) (7). There was a reduction in bleeding risk from $43 \%$ in the propranolol group to $15 \%$ in the ligation group after 18 months $(\mathrm{P}=0.04)$. There was also a trend toward fewer hospitalizations and fewer blood transfusions in the ligation group. Mortality rates were similar (11\%) in the two groups. The rate of bleeding in the propranolol group was higher than in other studies; this may have been due to the relatively low medication dosage in this group, although a $25 \%$ reduction in heart rate confirmed that beta-blockade was achieved successfully, at least during the initial stages of the trial. It is possible that inadequate dosing or noncompliance (especially later in the study) resulted in exceptionally high rates of bleeding in the propranolol group.

Two meta-analyses have recently been reported concerning band ligation as primary prophylaxis (8). The first metaanalysis analyzed five trials, involving a total of 601 patients, and compared band ligation with no active treatment in the primary prevention of variceal hemorrhage. All patients had large esophageal varices and one-third of patients had Child-Pugh class C cirrhosis. A significant decrease in the risk of first hemorrhage was documented in four studies. Two studies found that band ligation conferred a survival advantage, but mortality rates in the control groups were inordinately high in both studies. Band ligation

\section{REFERENCES}

1. Lebrec D. Primary prevention of variceal bleeding. What's new? Hepatology 2001;33:1003-4. (Edit)

2. Pagliaro L, D'Amico G, Sorensen TIA, et al. Prevention of first bleeding in cirrhosis. A meta-analysis of randomized trials of nonsurgical treatment. Ann Intern Med 1992;117:59-70.

3. Hayes PC, Davis JM, Lewis JA, Bouchier IA. Meta-analysis of value of propranolol in prevention of variceal haemorrhage. Lancet 1990;336:153-6.

4. Poynard T, Calès P, Pasta L, et al. Beta-adrenergic-antagonist drugs in the prevention of gastrointestinal bleeding in patients with cirrhosis and esophageal varices. An analysis of data and prognostic factors in 589 patients from four randomized clinical trials. N Engl J Med 1991;324:1532-8. reduced the relative risk of bleeding by $64 \%$ and the relative risk of death by $45 \%$. This meta-analysis showed that band ligation was superior to no active treatment in primary prophylaxis.

The second meta-analysis examined four trials, including 283 patients, and compared band ligation with propranolol. The risk of bleeding was lower in the ligation group in only one study. Nevertheless, the risk of bleeding was reduced by $48 \%$ with band ligation compared with propranolol. Overall mortality was similar with the ligation and propranolol treatments (17\% and $19 \%$, respectively), and there was no difference in the mortality rates due to bleeding. Thus, band ligation, when compared with propranolol, reduced the risk of variceal bleeding but did not reduce mortality. This finding suggests that propranolol may offer benefits other than a reduction in variceal hemorrhage for patients with liver disease. The number of patients required in a clinical trial to demonstrate a statistically significant advantage for band ligation over propranolol appears to be very large; it has been stated that a sample size of more than 1000 patients may be necessary (1). There are, as yet, no peer-reviewed studies published in full article form comparing these two modalities with respect to cost, side effects or quality of life. Band ligation may be associated with more adverse effects, such as ulceration with bleeding, infection and esophageal strictures, than are beta-blockers.

\section{CONCLUSIONS}

Beta-blockers are of proven benefit for the prevention of first variceal hemorrhage. Surgery and sclerotherapy are less suitable, because of adverse effects. Band ligation therapy is clearly superior to no active treatment for primary prophylaxis. The current data do not, however, demonstrate a reduced risk of bleeding compared with beta-blockers, except in one study. Furthermore, band ligation does not enhance survival compared with beta-blockers. Given that beta-blockers are inexpensive, widely available, convenient and generally very safe, they should be used for primary prophylaxis against variceal hemorrhage. Band ligation should be reserved for patients who are unwilling or unable to take beta-blockers.

5. Lay CS, Tsai Y-T, Teg C-Y, et al. Endoscopic variceal ligation in prophylaxis of first variceal bleeding in cirrhotic patients with highrisk esophageal varices. Hepatology 1997;25:1346-50.

6. Lo GH, Lai KH, Cheng JS, Lin CK, Hsu PI, Chiang HT. Prophylactic banding ligation of high-risk esophageal varices in patients with cirrhosis: A prospective, randomized trial. J Hepatol 1999;31:451-6.

7. Sarin SK, Lamba GS, Kumar M, Misra A, Murthy NS. Comparison of endoscopic ligation and propranolol for the primary prevention of variceal bleeding. N Engl J Med 1999;340:988-93.

8. Imperiale TF, Chalasani N. A meta-analysis of endoscopic variceal ligation for primary prophylaxis of esophageal variceal bleeding. Hepatology 2001;33:802-7. 


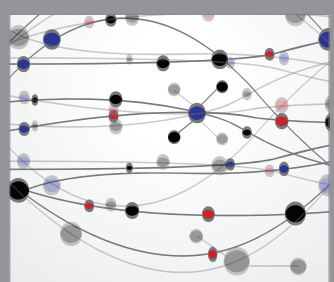

The Scientific World Journal
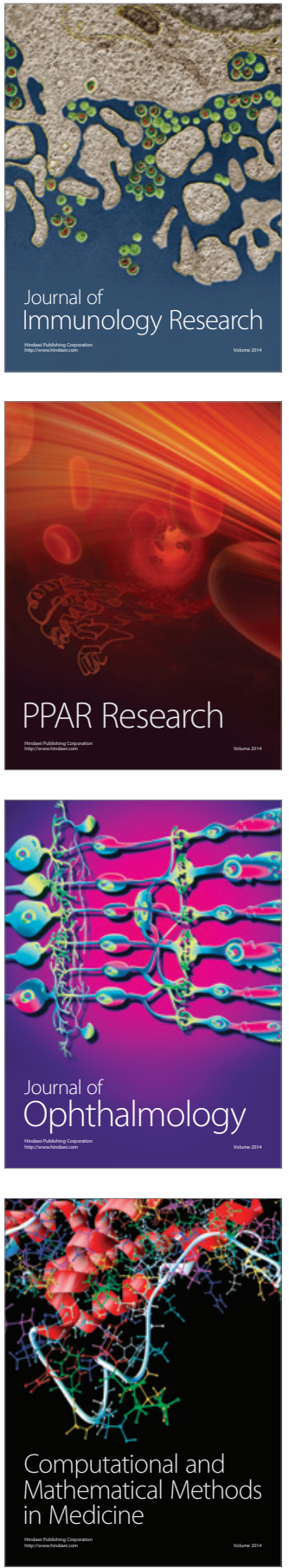

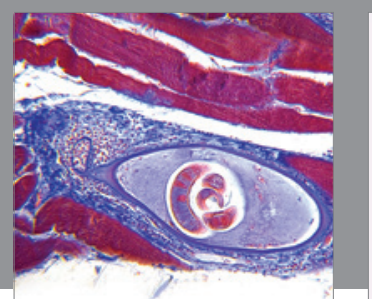

Gastroenterology Research and Practice

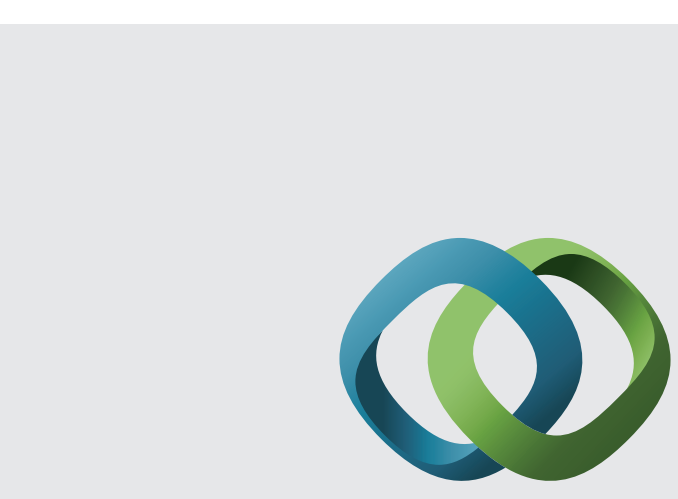

\section{Hindawi}

Submit your manuscripts at

http://www.hindawi.com
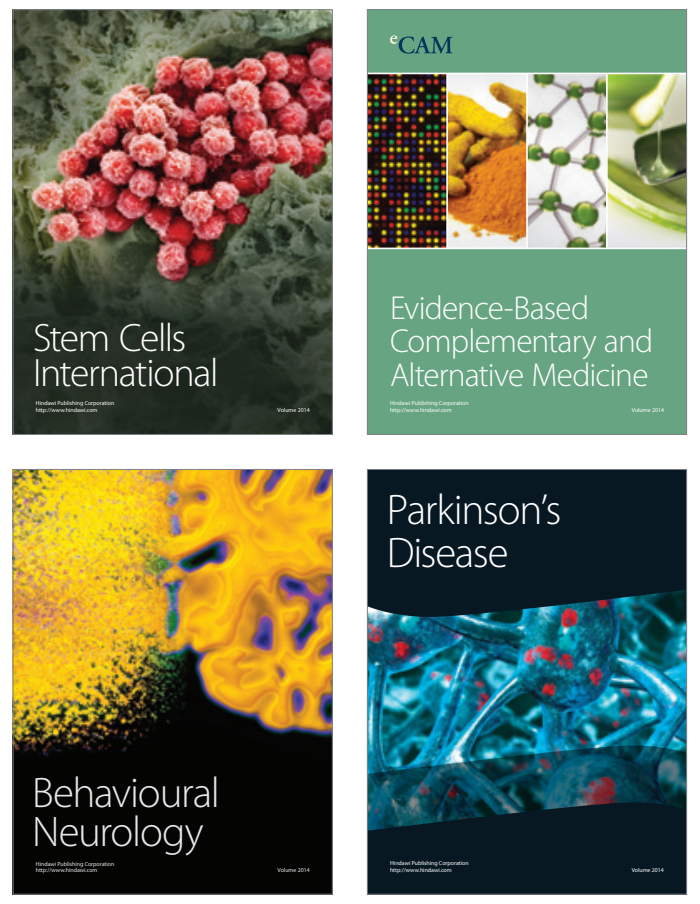
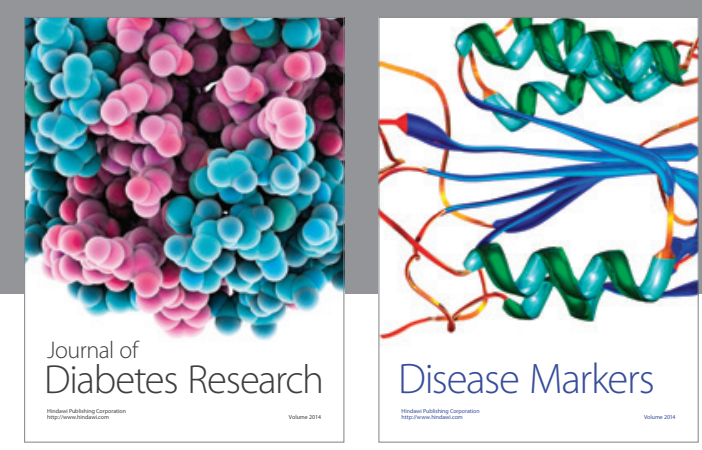

Disease Markers
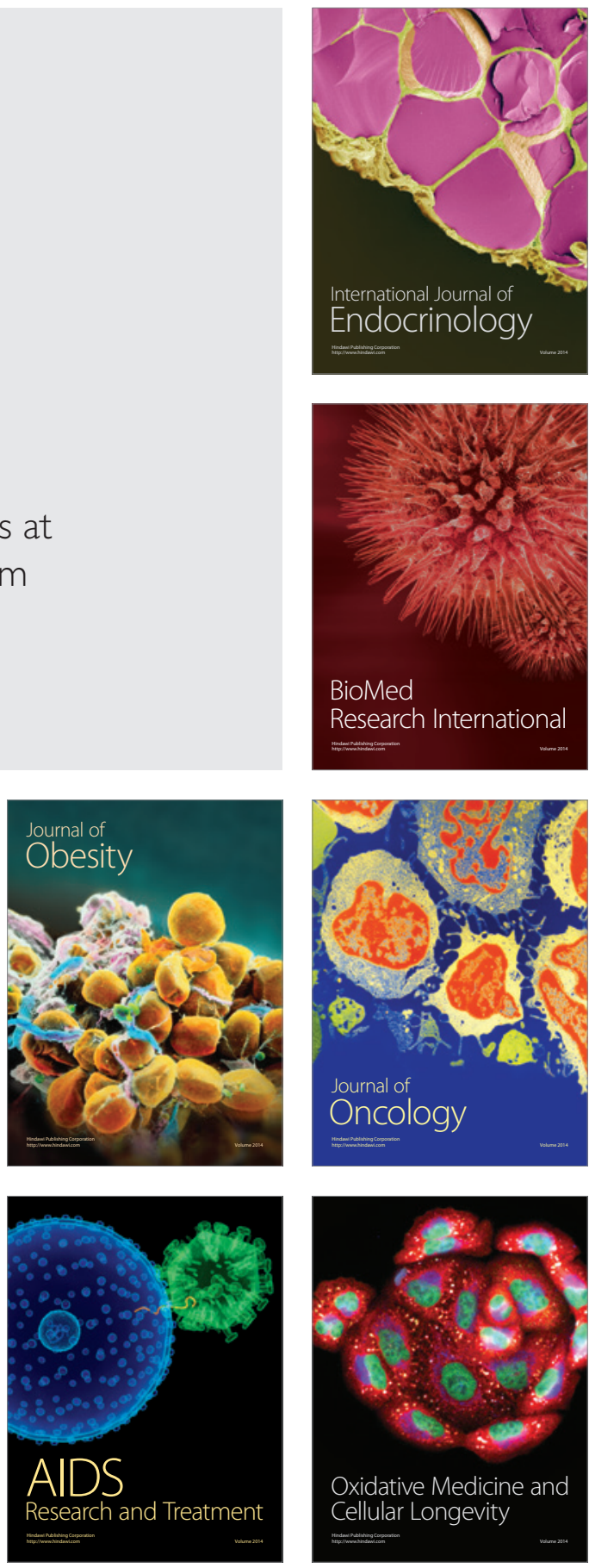